\title{
PERBANDINGAN NILAI KLOROFIL-A MENGGUNAKAN CITRA LANDSAT DAN MERIS DI DANAU SENTANI, JAYAPURA
}

\section{COMPARISON CHLOROPHYLL-A VALUES USE LANDSAT AND MERIS IN SENTANI LAKE ,JAYAPURA}

\author{
Jayeng Rangga Bhirawa ${ }^{1}$, Lalu Muhamad Jaelani ${ }^{1}$ \\ ${ }^{1}$ Institut Teknologi Sepuluh Nopember Surabaya \\ Email: Imjaelani@geodesy.its.ac.id
}

\begin{abstract}
Abstrak
Waduk dan Danau sangat penting dalam turut menciptakan keseimbangan ekologi dan tata air. Dari sudut ekologi, waduk dan danau merupakan ekosistem yang terdiri dari unsur air, kehidupan akuatik, dan daratan yang dipengaruhi tinggi rendahnya muka air, sehingga kehadiran waduk dan danau akan mempengaruhi tinggi rendahnya muka air, selain itu, kehadiran waduk dan danau juga akan mempengaruhi iklim mikro dan keseimbangan ekosistem di sekitarnya. Dalam penelitian ini, dilakukan perbandingan klorofil-a sebagai salah satu parameter kualitas air dengan menggunakan data Meris dan Landsat Parameter kualitas air dalam sifat fisiknya yang dapat dimodelkan secara optis antara lain yaitu Total Suspended Solid (TSS), Klorofil-a, dan Collored Dissolved Organic Matter(CDOM), dan lain-lain. Tetapi pada penelitian ini hanya difokuskan untuk klorofil-a. Penelitian ini bertujuan untuk melihat citra manakah yang lebih sesuai untuk digunakan penelitian kualitas air pada danau sentani selanjutnya. Untuk algoritma dalam pengolahan citra Landsat, hanya Algoritma Jaelani paling mendekati C2WP-Eut yaitu dengan R2 = 0,795; RMSE = 0,399 dan $\mathrm{RE}=16,087$
\end{abstract}

Kata Kunci: Danau Sentani, Klorofil-a, Landsat, MERIS, Algoritma

\begin{abstract}
Reservoirs and lakes are very important in helping to make the balance of ecology and hydrology. From the point of ecology, reservoirs and lakes is an ecosystem that consists of elements of water, aquatic life, and land which affected by water surface height, so the presence of reservoirs and lakes will affect the level of the water surface, in addition, the presence of reservoirs and lakes also affect micro climate and balance of the surrounding ecosystem .

Analysis of the spatial distribution of water quality parameters using Landsat Data MERIS and water quality parameters in the physical properties that can be modeled optically among others, Total Suspended Solid (TSS), Chlorophyll-a, and Collored Dissolved Organic Matter (CDOM). But in this study only for Chlorophyll-a

This study is looking for which image processing is suitable for Sentani Lake, In Algorithm for Landsat Image Processing, only the value of Jaelani Algorithms closest to C2WP-EUT with $R 2=0,795 ; R M S E=0,399$ and $R E=16,08 \%$ .And only Chlorophyll-A Reg-Eut associated with an average $R 2=0,807 ; R M S E=0,682$ and $R E=21,02 \%$.
\end{abstract}

Keywords: Sentani Lake, Chlorohyll-a, Landsat, MERIS, Algorithms

\section{PENDAHULUAN}

\section{Latar Belakang}

Tantangan dalam penyediaan sumber daya dewasa ini adalah bagaimana mencapai keberlanjutan ketersediaan sumber daya air baik dari segi kuantitas maupun kualitas dengan memperhatikan pengelolaan yang menjaga sumber daya tersebut dari pemanfaatannya yang merusak. Keberadaan waduk dan danau sangat penting dalam turut menciptakan keseimbangan ekologi dan tata air. Dari sudut ekologi, waduk dan danau merupakan ekosistem yang terdiri dari unsur air, kehidupan akuatik, dan daratan yang dipengaruhi tinggi rendahnya muka air, sehingga kehadiran waduk dan danau akan mempengaruhi tinggi rendahnya muka air, selain itu, kehadiran waduk dan danau juga akan mempengaruhi iklim mikro dan keseimbangan ekosistem di sekitarnyaPengerukan penting dilakukan secara regular minimal 3 bulan, khususnya untuk perawatan kolam di pelabuhan-pelabuhan yang 
sedimentasinya tinggi yang banyak membawa material erosi atau sampah dari hulu sungai. Berdasarkan fungsi tersebut, banyak faktor yang perlu dipertimbangkan dalam perencanaan pengerukan kolam pelabuhan.

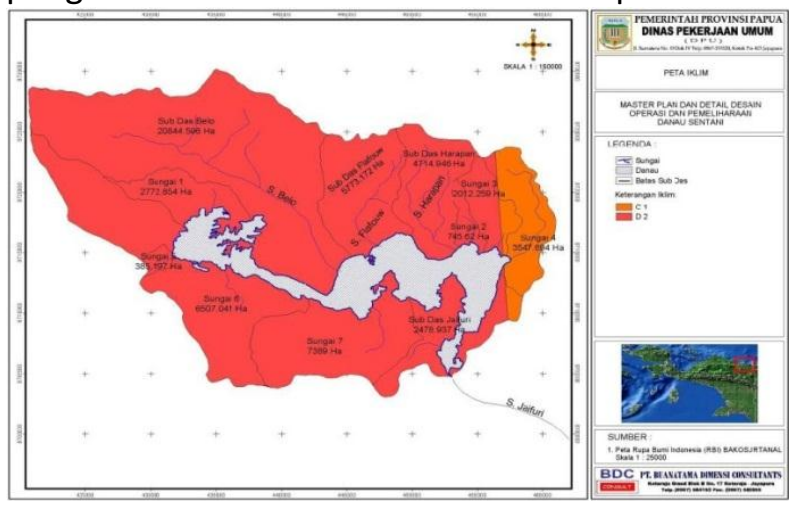

Gambar 1 Peta Kawasan Danau Sentani (Sumber : Profil 15 Danau Prioritas Nasional 2009-2014)

Danau Sentani yang memiliki luas 9.630 hektar (ha) dan kedalaman $70 \mathrm{~m}$ dpl merupakan satu kesatuan dengan Cagar Alam Pegunungan Cycloops (Jayapura) yang berareal 245.000 ha. Pegunungan Cycloops yang berbatasan dengan Kota Jayapura ditetapkan menjadi cagar alam (tahun 1995), sebagai pusat penelitian, dan pengembangan ilmu pengetahuan.

Danau Sentani mendapatkan suplai dari sekitar ¥34 sumber mata air dari pegunungan Cycloop. Sumber air danau ini berasal dari 14 sungai besar dan kecil. Luas daerah tangkapan air danau sekitar 600 km2. Ada satu muara yaitu Sungai Djaifuri yang terletak di sebelah Timur (daerah Puay). Beberapa inlet Danau Sentani yaitu Sungai Belo, Sungai Flafouw, dan Sungai Harapan.

\section{METODOLOGI PENELITIAN}

\section{Data Dan Peralatan}

\section{- Data}

Data yang digunakan dalam penelitian ini adalah :

1. Landsat tanggal 31 Mei 2003

2. Meris tanggal 3 Juni 2003

\section{- Peralatan}

Peralatan yang digunakan dalam penelitian ini adalah:

1. Perangkat lunak VISAT 5.0 dan ArcGIS 10.2.2

\section{Metode Penelitian}

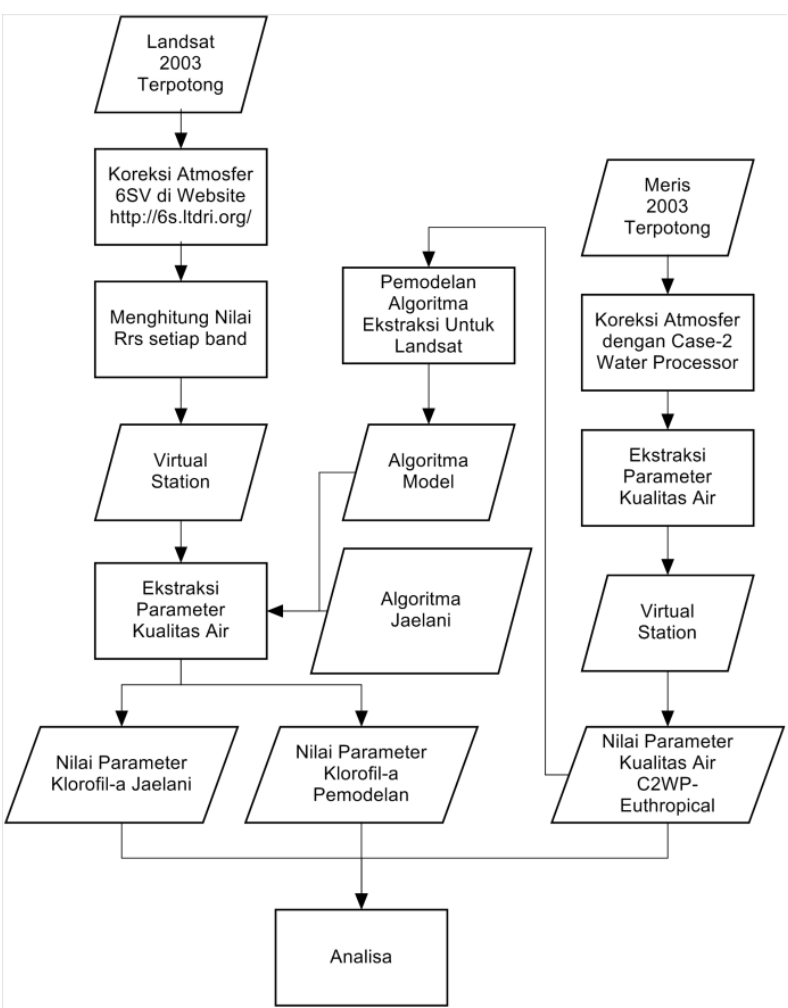

Gambar 2 Tahapan Pengolahan

a. Koreksi Atmosfer

Algoritma koreksi atmosfer dalam tahap ini digunakan untuk menghitung nilai reflektan . Algoritma yang digunakan adalah Algoritma C2WP untuk MERIS dan 6S untuk Landsat. yang menjadi patokan adalah C2WP-Euthropical lakes Processor dan algoritma itu selanjutnya menjadi patokan untuk Keperluan Estimasi nilai parameter menggunakan nilai reflektan dari Landsat.

Karena data Landsat dalam format radian, selanjutnya akan dikoreksi dari efek atmosfer menggunakan parameter koreksi dari hasil simulasi 6SV. Adapun parameter koreksi yang diperlukan adalah:

$$
\begin{aligned}
a c r_{\lambda}= & y_{\lambda} /\left(1+X c_{\lambda} * y_{\lambda}\right) \\
& y_{\lambda}=X a_{\lambda} *\left(L_{\lambda}\right) * X b_{\lambda}
\end{aligned}
$$

$\mathrm{L}_{\lambda}=$ nilai radiance yang terukur $(\mathrm{w} / \mathrm{m} 2 / \mathrm{sr} / \mathrm{mic})$

Untuk mendapatkan nilai Rrs dari 6S yang dijalankan menggunkan perangkat lunak berbasis web yang ada di http://6s/tdri.org/ .untuk mendapat nilai $\mathrm{Xa}, \mathrm{Xb}, \mathrm{Xc}$ yang setelah itu di 
jalankan pada rumus (4) dan (5) dan setelah itu untuk mendapatkan Rrs yaitu:

$$
\operatorname{Rrs}=a c r \times \pi^{-1}
$$

\section{b. Ekstraksi Nilai Parameter Kualitas Air}

Setelah mendapatkan nilai reflektannya, setelah itu dapat dilakukan Perhitungan Nilai Chl-a, TSS, dan CDOM diterapkan pada setiap data citra sebagai model optis dari parameter kualitas air.

Untuk Landsat ada 2 cara ekstraksi yakni dengan algoritma Chl-a Jaelani, membuat algoritma model dari nilai ekstraksi yang dilakukan dengan Case-2 water processor dari koreksi atmosfer C2WP-Euthrophical. Berikut adalah Algoritma Ekstraksi Pada Landsat:

$C h l-a_{\text {Jaelani }}=0,9889\left(\frac{E T M \text { Eand } 3}{\text { ETMBand } 4}\right)-0,3619$

ETM Band adalah Nilai Reflektan permukaan dari Band yang terukur pada Landsat. Sedangkan dari C2WP-Eutrophical adalah sebagai berikut:

Chl $-a=62,6 \times a_{\text {pig(443) }}^{1,29}$

$a_{\text {pig(443) }}$ adalah koefesien absorpsi dari fitoplankton.

\section{HASIL DAN PEMBAHASAN}

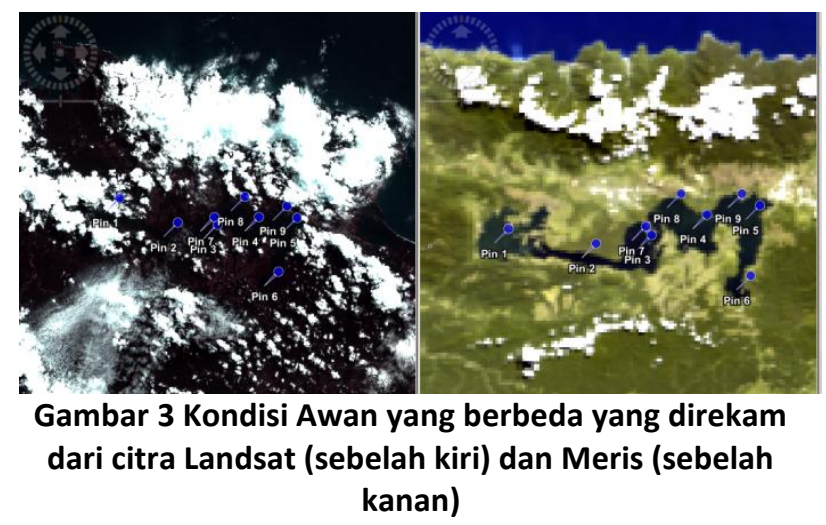

Sedangkan untuk hasil dengan algoritma referensi yaitu sebagai berikut:

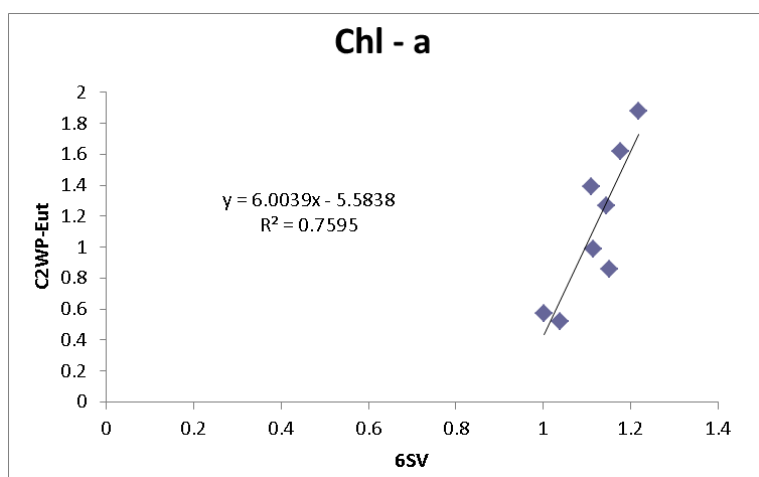

Gambar 4 Perbandingan Nilai Chl-a dari algoritma C2WP Eutrophical dengan Algoritma Chl-a Jaelani

Nilai hubungan dari beberapa algoritma ekstraksi parameter fisik air ini menunjukkan nilai yang sangat rendah. Dan menunjukkan tidak adanya hubungan dengan algoritma C2WP Eutrophical. Sedangkan untuk nilai RMSE dan RE-nya adalah sebagai berikut:

Tabel 1 Nilai Klorofil-a Landsat Jaelani dan Meris Eut beserta RMSE dan RE -nya

\begin{tabular}{lcc}
\hline & $\begin{array}{c}\text { 31 Mei } \mathbf{2 0 0 3} \\
\text { Landsat-Jaelani }\end{array}$ & $\begin{array}{c}\text { 3 Juni } 2003 \\
\text { Meris-Eut }\end{array}$ \\
\hline $\operatorname{pin} 1$ & & \\
$\operatorname{pin} 2$ & $1,038 \mathrm{mg} / \mathrm{m}^{3}$ & $0,521 \mathrm{mg} / \mathrm{m}^{3}$ \\
$\operatorname{pin} 3$ & $1,114 \mathrm{mg} / \mathrm{m}^{3}$ & $0,988 \mathrm{mg} / \mathrm{m}^{3}$ \\
$\operatorname{pin}(2)$ & $1,177 \mathrm{mg} / \mathrm{m}^{3}$ & $1,618 \mathrm{mg} / \mathrm{m}^{3}$ \\
$\operatorname{pin} 5$ & $1,217 \mathrm{mg} / \mathrm{m}^{3}$ & $1,877 \mathrm{mg} / \mathrm{m}^{3}$ \\
$\operatorname{pin} 6$ & $1,002 \mathrm{mg} / \mathrm{m}^{3}$ & $0,571 \mathrm{mg} / \mathrm{m}^{3}$ \\
$\operatorname{pin} 7$ & $1,150 \mathrm{mg} / \mathrm{m}^{3}$ & $0,859 \mathrm{mg} / \mathrm{m}^{3}$ \\
$\operatorname{pin} 8$ & $1,110 \mathrm{mg} / \mathrm{m}^{3}$ & $1,389 \mathrm{mg} / \mathrm{m}^{3}$ \\
$\operatorname{pin} 9$ & $1,144 \mathrm{mg} / \mathrm{m}^{3}$ & $1,269 \mathrm{mg} / \mathrm{m}^{3}$ \\
\hline RMSE & 0,399 & \\
\hline RE & $16,08 \%$ \\
\hline
\end{tabular}

Dengan data yang berbeda 3 hari dan kondisi cuaca yang kemarau, dapat diasumsikan bahwa kondisi fisik dari air danau tersebut masih sesuai untuk dibandingkan. Karena kondisi awan yang berbeda, nilai pin 1 tidak ikut di hitung. Sehingga hanya 8 titik yang akan dibandingkan. 


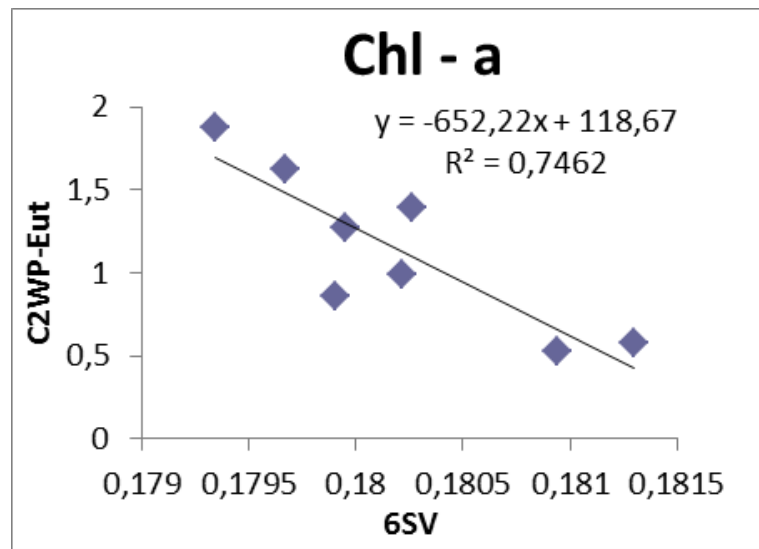

Gambar 5 Perbandingan Nilai Chl-a dari algoritma C2WP Eutrophical dengan Modelnya

Terlihat pada gambar 5 bahwa hubungan yang dekat yaitu yaitu 0,7462 , dan rata-rata lebih dari $50 \%$. Tetapi untuk lebih baiknya dapat dilihat hasil RMSE dan RE-nya.

Tabel 2 Nilai Klorofil-a Landsat Model dan Meris Eut beserta RMSE dan RE -nya

\begin{tabular}{ccc}
\hline & $\begin{array}{c}\text { 31 Mei 2003 } \\
\text { Lansdat-Model }\end{array}$ & $\begin{array}{c}\text { 3 Juni } 2003 \\
\text { Meris Eut }\end{array}$ \\
\hline pin 1 & & \\
pin 2 & $0,1809 \mathrm{mg} / \mathrm{m}^{3}$ & $0,5218 \mathrm{mg} / \mathrm{m}^{3}$ \\
pin 3 & $0,1802 \mathrm{mg} / \mathrm{m}^{3}$ & $0,9885 \mathrm{mg} / \mathrm{m}^{3}$ \\
$\operatorname{pin} 4$ & $0,1796 \mathrm{mg} / \mathrm{m}^{3}$ & $1,6189 \mathrm{mg} / \mathrm{m}^{3}$ \\
$\operatorname{pin} 5$ & $0,1793 \mathrm{mg} / \mathrm{m}^{3}$ & $1,8771 \mathrm{mg} / \mathrm{m}^{3}$ \\
pin 6 & $0,1812 \mathrm{mg} / \mathrm{m}^{3}$ & $0,5710 \mathrm{mg} / \mathrm{m}^{3}$ \\
$\operatorname{pin} 7$ & $0,1799 \mathrm{mg} / \mathrm{m}^{3}$ & $0,8596 \mathrm{mg} / \mathrm{m}^{3}$ \\
pin 8 & $0,1802 \mathrm{mg} / \mathrm{m}^{3}$ & $1,3894 \mathrm{mg} / \mathrm{m}^{3}$ \\
pin 9 & $0,1799 \mathrm{mg} / \mathrm{m}^{3}$ & $1,2697 \mathrm{mg} / \mathrm{m}^{3}$ \\
\hline RMSE & 1,059 & \\
\hline RE & $80,82 \%$ & \\
\hline
\end{tabular}

Kondisi ini menunjukkan bahwa algoritma yang diterapkan pada Chl-a masih perlu untuk dikaji kembali kesesuaian algoritma tersebut dengan kondisi lingkungan pada daerah Danau Sentani. Karena nilai RMSE 1,059 merupakan nilai yang berpotensi memiliki kesalahan yang lebih besar lagi.

\section{PENUTUP}

\section{Kesimpulan}

Dari beberapa hasil dan diskusi yang telah dilakukan, kesimpulan yang didapat adalah sebagai berikut : a. Metode yang paling baik untuk menentukan ekstraksi parameter air danau Sentani adalah menggunakan data Meris dan menggunakan Case-2 Water Processor-Eutrophical.

b. Hanya algoritma Jaelani untuk ekstraksi nilai Klorofil-a dari data landsat yang berhubungan dengan Case-2 Water Processor - Eutrophical dengan RMSE = 0,$399 ; \mathrm{RE}=16,087$ dan $\mathrm{R}^{2}=0,795$.

\section{Saran}

Saran untuk Penelitian berikutnya adalah perlu adanya kajian lebih lanjut untuk adanya algoritma yang sesuai untuk ekstraksi parameter kualitas air danau Sentani untuk citra Landsat. Karena kebutuhan akan resolusi spasialnya yang bagus untuk menganalisa penyempitan yang terjadi pada danau Sentani ini membuat citra Landsat masih dibutuhkan untuk penelitian lebih lanjut.

\section{UCAPAN TERIMAKASIH}

Penulis mengucapkan banyak terima kasih kepada semua pihak yang telah turut membantu atas terselesaikannya penelitian ini, terutama kepada Ibu Dian dari Jurusan Biologi ITS atas bantuan data lapangan. Tak lupa juga penulis mengucapkan terima kasih kepada dosen pembimbing Bapak Jaelani serta teman-teman satu tim penelitian.

\section{DAFTAR PUSTAKA}

Alfina, Tahta, Santosa, B., and Barakbah, R. 2012. "Analisa Perbandingan Metode Hierarchical Clustering, K-Means Dan Gabungan Keduanya Dalam Cluster Data ( Studi Kasus : Problem Kerja Praktek Jurusan Teknik Industri ITS )." Jurnal Teknik ITS 1.

Anonymous. Sebuah Perspektif tentang Kejadian Pemutihan Tahun 2010 http://id.coralwatch.org (29 Oktober. 2014)

Anonymous, 2013. Laporan Akhir Identifikasi Kerusakan Ekosistem Terumbu Karang. Kerjasma antara Badan Lingkungan Hidup Provinsi Jawa Timur dan Lembaga Penelitian dan Pengabdian Masyarakat (Institut Teknologi Sepuluh Nopember Surabaya 2013)

Burke L , E . S elig, and M. Spalding. 2002. Reefs at R isk in Southeast Asia. 72 pp. World Resources Institute, Washington, D.C. 


\section{LAMPIRAN}

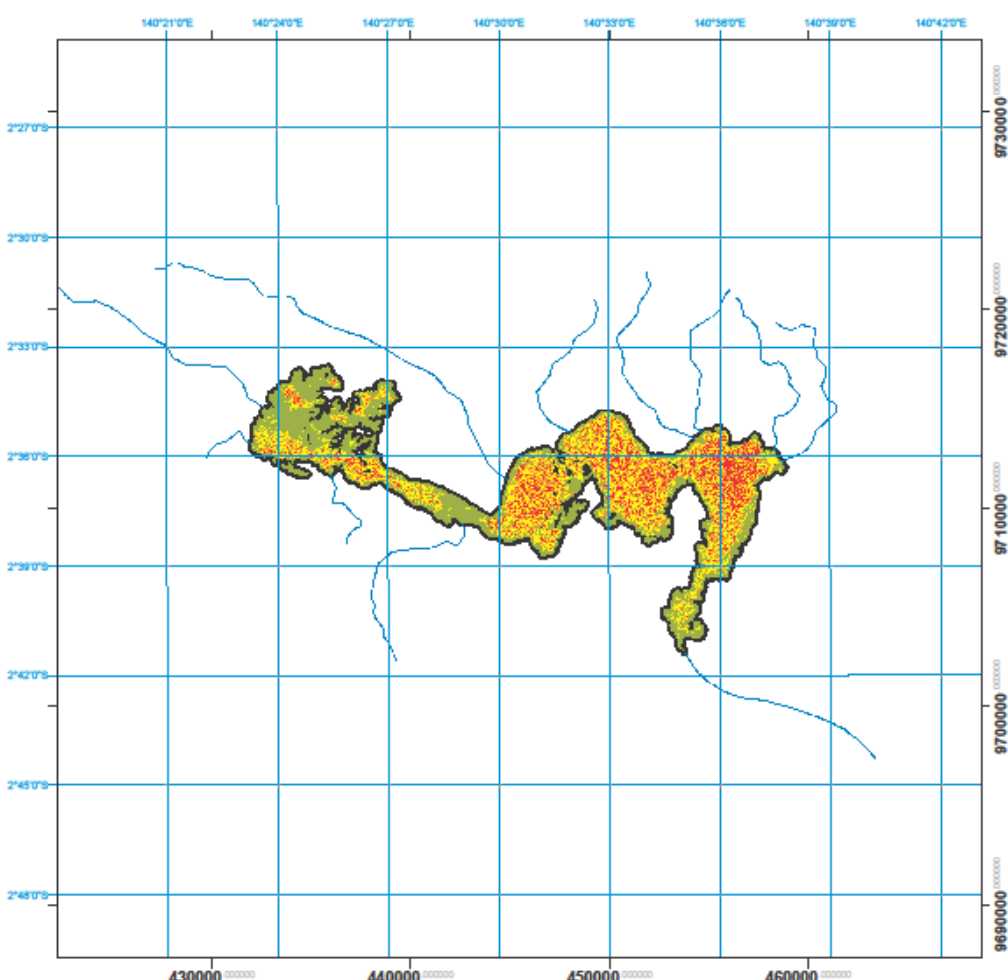

PETA PERSEBARAN KLOROFIL-A 31 MEI 2003

DANAU SENTANI,JAYAPURA

6SV-JAELANI

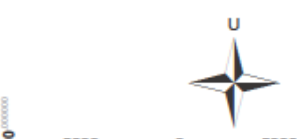

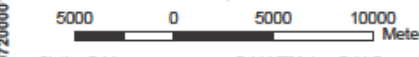
Sistim Grid
Proyeksi
Satuan Yang Dipakai

Spasial A.
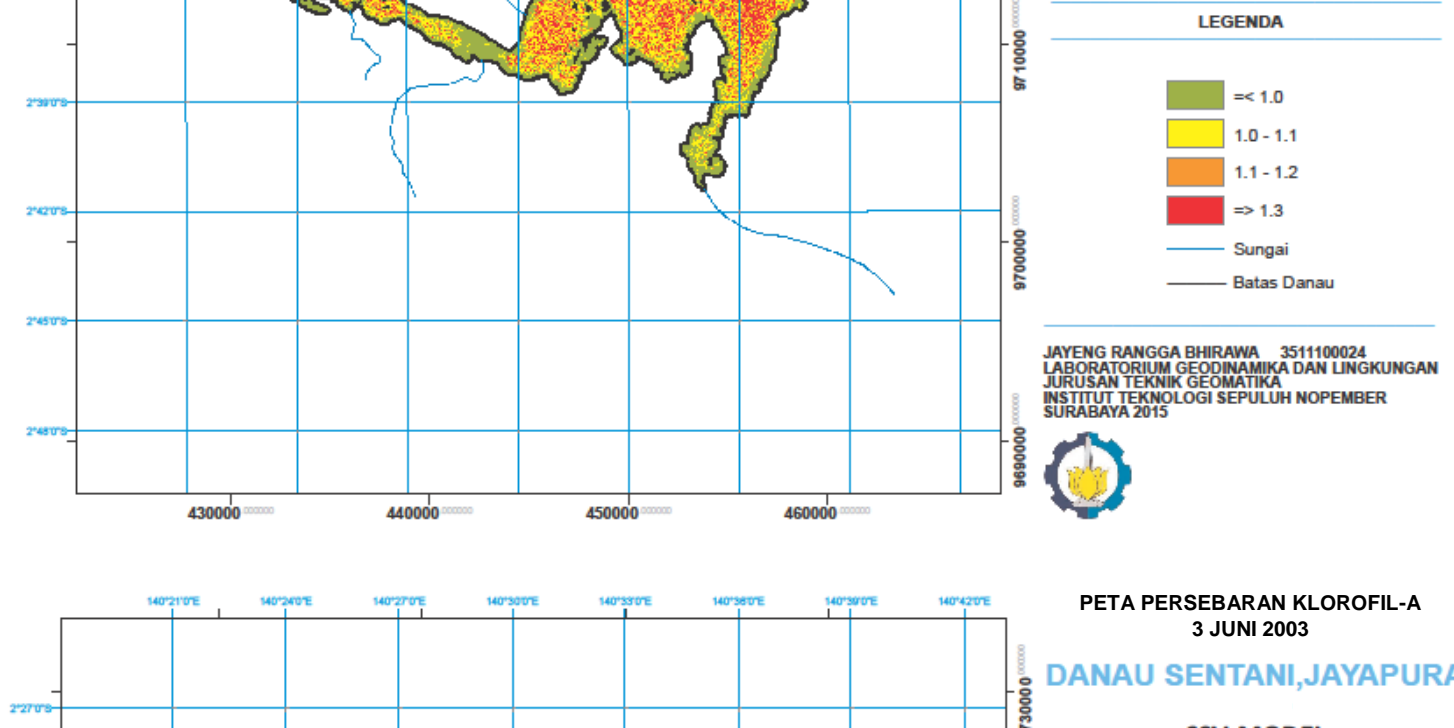

PETA PERSEBARAN KLOROFIL-A 3 JUNI 2003

DANAU SENTANI,JAYAPURA

6SV-MODEL

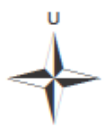

\begin{tabular}{llll}
5000 & 0 & 5000 & 10000 \\
\hline & & &
\end{tabular} Sistim Grid $\quad: . .$. Grid UTM dan Grid Geografi Satuan Yang Dipaka :

Ppasial Meter
$\mathrm{mg} / \mathrm{L}$ LEGENDA

훙
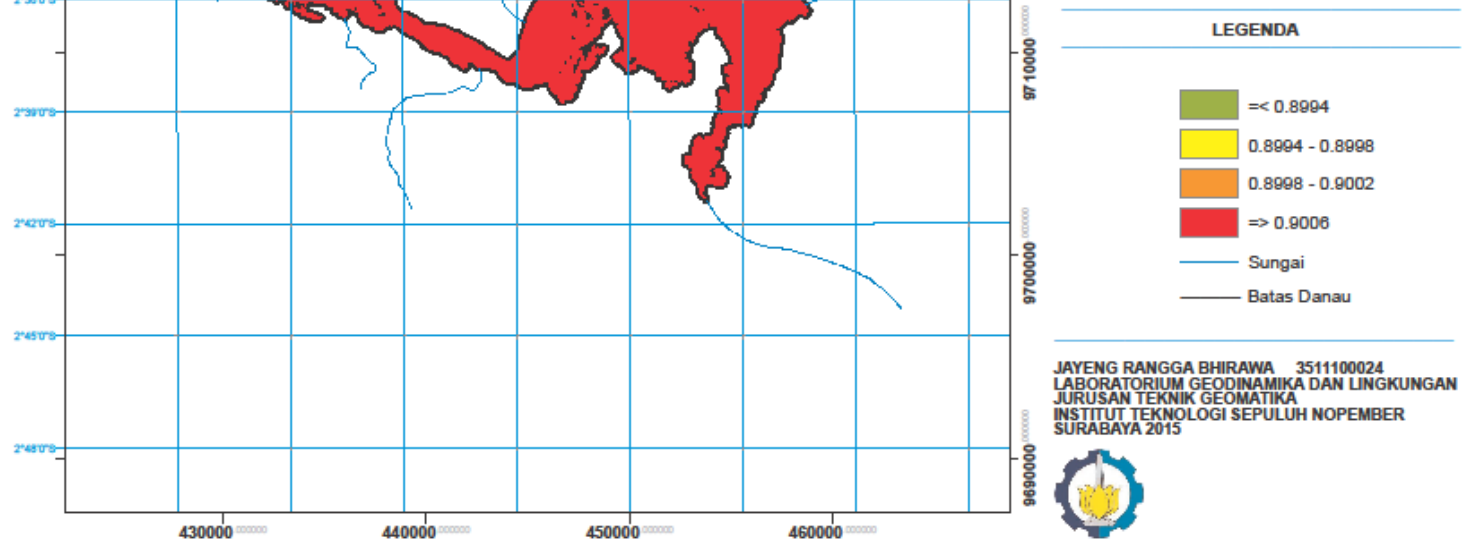

- Batas Danau

JAYENG RANGGA BHIRAWA 3511100024 URUSAN TEKNIK GEOMATIKA DAN UNGKUNC NSTTIUT TEKNOLOGI SEPULUH NOPEMBER 


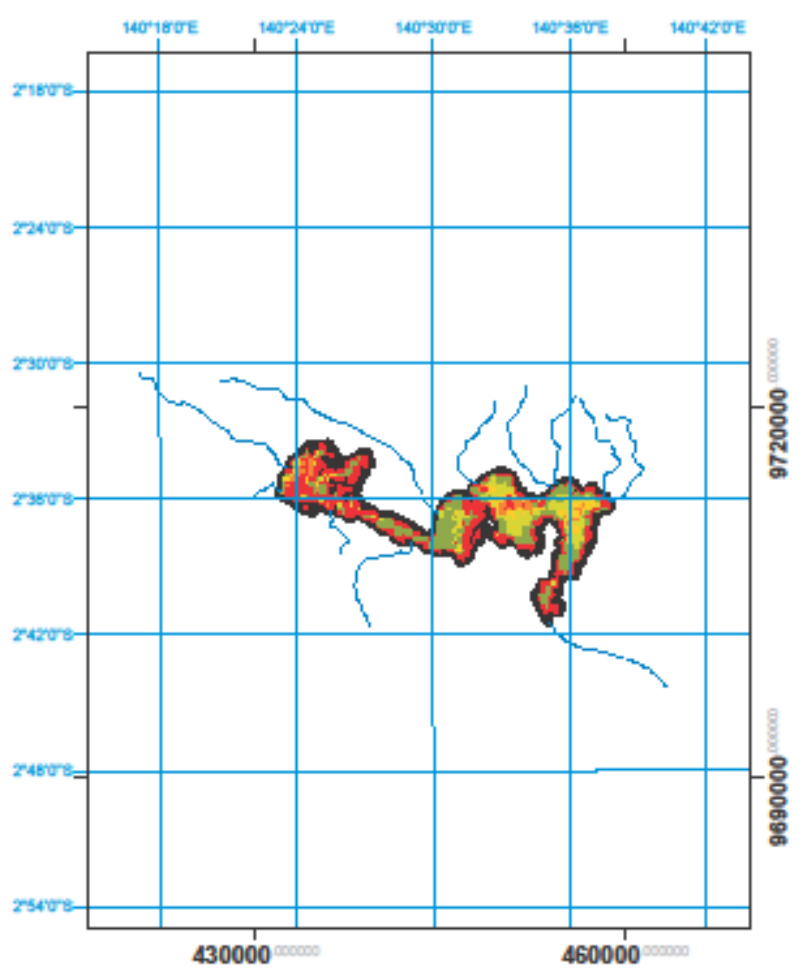

PETA SEBARAN CHL 3 JUNI 2003 DANAU SENTANI,JAYAPURA

Euthropical

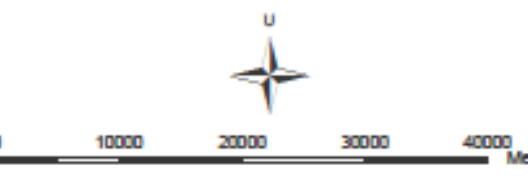

Sistim Grid Satuan Yang Dipakai Spasial Parameter Air : .-.- Grid UTM dan Grid Geografi

LEGENDA

\begin{tabular}{|ll}
\hline & $\times 1.25$ \\
$1.25-1.5$ & \\
$1.5-1.75$ & \\
& $1.75-2$ \\
$2-2.25$ &
\end{tabular}

JAYENG RANGGA BHIRAWA 3611100024 LABORATORIUM GEODINAMIKA DAN LINOKUMMAN (1) 